\title{
Activity limitations and participation restrictions experienced by people with stroke in Musanze district in Rwanda
}

\author{
Gerard Urimubenshi
}

\author{
Department of Physiotherapy, University of Rwanda, Rwanda
}

\begin{abstract} district in Rwanda. survivors.

DOI: http://dx.doi.org/10.4314/ahs.v15i3.28 Afri Health Sci. 2015;15(3):917-24. doi: http://dx.doiorg/10.4314/abs.v15i3.28

\section{Introduction}

Stroke is a major cause of long-term disability. The outcome of stroke is as follows: one year after a stroke, about $30 \%$ of patients will be dead, and of the survivors, almost $40 \%$ will be dependent on others for their daily activities ${ }^{1}$. Stroke has enormous emotional and socioeconomic consequences for patients, their families, and health services. Suffering a stroke challenges the assumptive identity, self-concept and role-capacity of the individual in the face of acquired deficits ${ }^{2}$, and the period following discharge from hospital or from inpatient rehabilitation is the most challenging for almost all stroke patients ${ }^{3}$. This could be associated with a discharge without accurate assessment of the domestic environment, and the establishment of networks
\end{abstract}

Background: Stroke is a major cause of long-term disability. Information regarding the limitations in activity and participation experienced by patients with stroke in a specific setting such as Musanze district in Rwanda would assist to develop the rehabilitation programmes that would take into consideration the functional challenges experienced post stroke.

Objective: To explore the activity limitations and participation restrictions experienced by people with stroke in Musanze

Methods: A qualitative phenomenological approach using in-depth face-to-face interviews with 10 participants was employed to gather the data that was analyzed using a qualitative thematic approach.

Results: The themes that arose as activity limitations included limitations in walking, self care, and domestic life activities. The themes related to participation restrictions as expressed by the participants were inability to return to previous occupation, decreased social interactions and inability to participate in religious activities.

Conclusion: The current study findings highlight the need for interventions to improve the functional status of stroke

Keywords: Stroke, activity limitations, participation restrictions, Musanze district, Rwanda

Cite as: Urimubenshi G. Activity limitations and participation restrictions experienced by people with stroke in Musanze district in Rwanda.

\author{
Correspondence author: \\ Gerard Urimubenshi \\ Department of Physiotherapy \\ College of Medicine and Health Sciences \\ University of Rwanda \\ P.O. Box 3286 \\ Kigali, Rwanda \\ Ph: +250788871371 \\ E-mail: ugerard@khi.ac.rw
}

to meet critical needs such as personal care and home modifications.

Understanding the challenges faced by those who have suffered a stroke is useful to identify the longer-term issues that primary care based services for stroke will need to address ${ }^{3}$. Studies which investigated the functional challenges experienced by stroke patients revealed that the main activity limitations experienced are inability to walk independently, dependence on bathing, eating and dressing, as well as in housework activities such as washing, cooking and cleaning ${ }^{4,5,6}$. A study conducted in South Africa to determine the limitations in activity and participation experienced by community-dwelling stroke survivors discharged from an intensive inpatient rehabilitation programme at 6 months post stroke revealed that many participants were not independent in housework, food preparation, shopping, and public transport use $\mathrm{p}^{7}$. Participation restrictions experienced are mainly the inability to return to the previous employment and social isolation ${ }^{2}$. Most of the studies about people with stroke were conducted in developed countries, and were quantitative cross-sectional in design. According to Dowswell et al. ${ }^{8}$, quantitative measures may be more relevant to the concerns of researchers than to those of patients for whom the subjective, lived experience of stroke is likely to be of greater importance. 
Stroke patients at Ruhengeri hospital in Rwanda which serves Musanze district are admitted in the intensive care unit or the general medical wards of the internal medicine. The stroke care consists of medical and physiotherapy management only. The evidence accumulated however shows that effective stroke rehabilitation requires a multidisciplinary team and equipped stroke units $^{9}$. The stroke patients discharged very early, and without follow-up rehabilitation services would likely experience a lot of functional limitations. In the absence of data on the potential burden of stroke, though, it is difficult to develop appropriate strategies to prevent stroke and its impact ${ }^{10}$. The researcher therefore decided to explore the limitations in activity and participation experienced by people with stroke in Musanze district in Rwanda.

\section{Methods}

\section{Study setting}

This study was conducted in Musanze district, in the Northern Province of Rwanda. The Musanze district is an area which is mainly rural, and where at least $91 \%$ of the population is engaged in agriculture ${ }^{11}$. Most families (about 65\%) live below the poverty line ${ }^{12}$. In addition, many families have been destroyed by the 1994 genocide and the repetitive 1997-1998 wars in the region, leaving survivors with disabilities, widows and orphans. Musanze is the most mountainous district in Rwan$\mathrm{da}^{13}$, and has therefore difficult geographical access and transport. In Musanze district, there are neither outreach nor community-based rehabilitation services that are provided to stroke patients. These can only get the institution-based rehabilitation services as inpatients or outpatients.

\section{Ethical considerations}

Ethical clearance for the study was obtained from both the Research Committee at the University of the Western Cape in South Africa and the National Ethics Committee of Rwanda. Permission to conduct this study was obtained from the Mayor of Musanze district. Written informed consent was obtained from each guardian and participant. Participation in the study was voluntary. For purposes of anonymity and confidentiality, the quotations of data from the interviews were cited using the cryptogram P1 to P10 rather than the participants' names.

\section{Study design}

A qualitative phenomenological approach using indepth interviews was employed to explore the activity limitations and participation restrictions experienced by people with stroke in Musanze district from their own point of view.

\section{Sample, inclusion and exclusion criteria}

A sample of 10 persons with stroke living in Musanze district was purposively selected. The characteristics that were considered for the purposive selection were age, gender, and chronicity of stroke. These characteristics were found to be significantly related to positive or negative adjustment and development of self-concept post-stroke, and would contribute to a richer variation of the phenomena under study ${ }^{14}$. The chronicity of stroke was calculated as the difference between the date of data collection and the date of stroke onset. Patients who still needed assistance at least for one activity were included. On the other hand, it was necessary to recruit subjects who were able to articulate their experiences and feelings, and accordingly exclude individuals with communication or cognition problems. To obtain respondents with experiences related to stroke, individuals who had suffered other major diseases after the initial stroke were excluded (for example head injury, osteoarthritis and rheumatoid arthritis).

\section{Data collection instrument}

All interviews were conducted by the researcher using an interview guide developed on basis of the study objective, the literature, together with the researcher's experience. The participants were asked to tell the story of their stroke and the way it had affected their lives, beginning with the question: "Please tell me about any functional problems you are having since you got the stroke". There was then a series of guided probes to obtain an in-depth description of the limitations in activity and participation experienced.

\section{Procedure for data collection}

After permission was obtained from the necessary authorities, the in-depth interviews in Kinyarwanda were conducted with the 10 participants in their homes.

To get 10 different participants, the patient who was contacted, and met the inclusion criteria, and agreed to participate in the study was recruited. All contacted subjects agreed to take part in the study and were willing and appreciative of the opportunity to relate their experiences. A convenient time and location was determined for the patient interviews which lasted on average 50 minutes. The rooms where the interviews were conducted were assessed before starting to ensure good quality recordings and without possible interruptions 
and distractions. All interviews were audiotape-recorded, and the research assistant took field notes.

\section{Data analysis}

The tape-recorded interviews in Kinyarwanda were fully transcribed by the researcher. The transcriptions were then read and compared to audio tape recordings and field notes several times to verify accuracy ${ }^{15}$. A trained, multilingual translator translated the transcriptions into English and the researcher analyzed those transcriptions to identify the main patterns of responses and consistencies and divergences across participants ${ }^{16}$. Common concepts were coded as suggested by Miles and $\mathrm{Hu}-$ berman ${ }^{17}$, producing themes. Two weeks after the initial coding, another separate coding was done and the generated themes in the second and first coding were then compared. This led to further refinements, producing themes that were interpreted for the meaning of the content.

\section{Trustworthiness of the data}

To establish the trustworthiness of the qualitative data, Shenton ${ }^{18}$ suggested the concepts of credibility, confirmability, transferability and dependability as essential decisive factors for quality in qualitative research. To enhance the four criteria, different strategies were employed.

To enhance credibility of the data, the themes presented were illustrated with representative quotations from the transcribed texts ${ }^{19}$. To ensure confirmability of the data, a peer examination was used by the researcher discussing the research process and findings with colleagues and experts who have experience in qualitative research methods ${ }^{20}$.

To enhance transferability of the data, a clear and distinct description of the study setting, the selection and characteristics of participants, data collection and process of analysis was used ${ }^{19}$. For this purpose, different characteristics that were considered to select informants included chronicity of stroke, gender, current age, and functional status (independent walking). To address the dependability of the data, the researcher has used a code-recode procedure during data analysis as suggested by Krefting ${ }^{21}$.

\section{Results}

\section{Participants' characteristics}

Five participants $(50 \%)$ were females and five others
$(50 \%)$ were males. The participants were aged between 24 and 79 years (mean age $=56.3$ years, $S D=16.9$ years). Half of the participants (50\%) were married while three $(30 \%)$ were widowed. The chronicity of stroke among the participants lies between 3 and 53 months (mean = 19 months, SD $=16.4$ months). Eighty percent of the participants were involved in manual activities before the stroke, and the majority $(60 \%)$ of them were cultivators before getting stroke. In Rwanda, agriculture is mainly for subsistence and is associated with low socioeconomic status.

\section{Activity limitations}

During the in-depth interviews, when participants were asked to describe the problems they were having since they got stroke, three themes related to activity limitations emerged: limitations in walking, limitations in selfcare activities, and limitations in domestic life activities.

\section{Limitations in walking}

Limitations in walking were described by the majority of the participants interviewed, and varied from total loss of walking to a decrease in independent walking. As a strategy to cope with the mobility limitations, the participants revealed using a wheelchair or a stick to move around their homes or walk within the community.

Participants who were not able to walk expressed the dramatic negative effect of the stroke on walking as reflected in the following quotes:

"Since I became sick, I have never been able to walk and I always use a wheelchair to go somewhere" (P2).

"... I have a problem of not being able to walk. To reach somewhere, they (caregivers) lift me in their arms" (P5).

Some participants revealed that although they were able to walk, their capacity to walk independently had been reduced as quoted below:

"... I feel sad that I cannot walk as before and I am always at home. You see....when I am walking it is like I am walking using one leg and I am pulling the other leg... When I walk out of the bouse I use a stick, but I can't go beyond that road"( P3).

"... I walk very slowly ... I am no longer able to walk for a long distance. When I am walking even with a stick, I become tired in a short time" (P10).

Various participants revealed that physical environments in Musanze district was contributing to the limitations in walking as one of the participants said: "...I cannot use my wheelchair out of the house because there are many stones outside there" (P9). 


\section{Limitations in self-care activities}

All the participants frequently raised dependence in self-care activities such as bathing, eating, going to toilet, and dressing. Participants expressed the need for assistance to carry out the self-care activities as quoted below:

"... I cannot feed myself without assistance ... Ob! I cannot even bath myself ... (P1)".

"... I cannot dress by myself. It is difficult to put on the belt or to close the buttons... my wife helps me" (P7).

The participants were psychologically affected by the issues around limitations in self-care activities. Some participants felt that it was shamefully to ask somebody to assist them in so basic daily activities. For example, a participant said:

"It is very sad to ask someone to bring me to the toilet. It is very shameful for me" (P1).

Many respondents were uncomfortable with their dependence in self-care and did not wish to burden their relatives, friends or volunteers, and this was a source of being psychologically affected in a way that the participants wondered why they did not die instead of living and burdening others. For instance, the participants expressed:

"... I cannot do anything for myself. You see, now it is my daughter in-law who is feeding me, washing me and dressing me. ... She is newly married with my son and now rather than working for their new family; she is always assisting me ... What they did for me is enough. I wish that I should go back to my home and wait my death" (some tears came out of the eyes) (P5).

"... I feel like being a burden to my family because I am being assisted in everything ... Better I should have died" (P8).

\section{Limitations in domestic life activities}

The participants did not only have problems with walking and self-care activities. They also displayed problems with domestic life activities such as cooking, washing clothes and cleaning the house. While some participants felt that they were able to do only part of the domestic activities, others expressed that they could not do anything. The need for assistance in domestic life activities was expressed by the participants as illustrated by the following quote:

"... I can cook, but I cannot get water myself and I cannot get food from the kitchen. When I am cooking, I call someone to come and help me" (P9).

Some participants revealed that they could not do any part of their domestic activities. For example, a participant said:
"... Oh, I cannot do anything with my hands ... when others bave gone to work, I try to see if I can clean the house, but it is very hard ... I cannot do it (expressed with emotion) (P4)"!

\section{Participation restrictions}

As domains of participation restrictions, the participants' expressions were related to three main themes which are the inability to return to previous occupation, decreased social interactions, and inability to participate in religious activities.

\section{Inability to return to previous occupation}

Participants reported that they were not able to return to their previous occupations as illustrated by the following quotes:

"... I was a cultivator and I used to work in my fields and my children were helping me, and now they are working alone... I cannot do anything" (P5).

"... I am always at home ... I am not able to go to cultivate as before getting sick. ...”(P3).

As a consequence of being unable to perform the income generating activities, the participants expressed their concern related to economical dependence as illustrated below:

"... You understand, now I cannot get money and I am being fed like a child (expressed with great emotion)" (P3).

"... Before I got sick I was a carpenter, now I cannot do it to get money, and I get what I need from my children" (P7).

While other interview participants cited their inability to return to their previous income generating activities, the participant who was a student before stroke expressed the challenge of not being able to further pursue studies as quoted below.

"I was in 3rd year of my secondary school studies. After I got sick, I stopped studying, and I don't know if I will go back to school again” (P1).

\section{Decreased social interactions}

The participants described the decreased social interactions when probed to tell if there was any change in their social relationships. Sub-themes related to decreased social interactions as felt by the participants included not being able to get out of the house, and being separated from the family and neighbors after leaving their homes for rehabilitation. For example, a participant who was not able to walk remarked:

"... I cannot reach where others are. I visit nobody. You understand it's very hard. I just sit in the house till somebody comes to see me" (P9). 
Also, some participants experienced the decreased social contact because they changed residences after having stroke, and this resulted in changes in their usual social relationships as described by the participants:

"... Now, I have moved from home to stay near the hospital to continue physiotherapy. It is difficult for my neighbors to come to visit me" (P8).

"My children come sometimes from home to visit me where I stay ... but they do not come always. It is very far; it is about one hour driving" (P5).

\section{Inability to participate in religious activities}

Participants expressed their concern of not being able to participate in religious activities, and the issues related to this as remarked by the participants were inability to walk and the pain associated with walking for those who were able to walk, as illustrated below:

"... I am a Pentecost, but after getting sick I have never been to church to pray God because I have difficulty to walk." (P10).

"... I rarely go to church because I cannot reach there by myself ... I have lost my Christianity! Since I got sick, I went to church few times. It is only possible when my husband is there and brings me to church in a car" (P2).

"... Normally I am an Adventist, but currently I do not go to pray ... When I walk for about one hour I feel much pain requiring stopping and resting ... It is very sad that I cannot go to pray" (P6).

\section{Discussion}

The study findings will be discussed under two sections which are activity limitations and participation restrictions experienced with reference to relevant literature and the context of the study setting.

\section{Activity limitations experienced}

The limitations in walking as expressed by the participants were also reported in similar studies. Twenty to twenty-five percent of all stroke survivors are unable to walk without full physical assistance ${ }^{22}$. Participants in a qualitative patient-centred study conducted in South Africa also reported decreased ability to walk independently among the challenges experienced post-stroke ${ }^{23}$. The inability to walk among the participants is not surprising given the stroke event which is commonly associated with weakness or paralysis in the legs, or problems with balance. Additionally, some characteristics of the living area of the participants such as mountains, uneven grounds or stones could be barriers for those who could walk independently. Independent walking is often used as an indicator of functional recovery in stroke ${ }^{24}$, and limitations in walking would cause other musculo-skeletal complications as well as further dependence in the activities of daily living and social isolation ${ }^{6}$. For instance being unable to walk would be a barrier to return to work, or to participate in different social events. The study findings therefore suggest the rehabilitation strategies aiming to improve the ability to walk among the study population.

When asked to describe the troublesome effects of the stroke, most of the feelings that spontaneously emerged in participants' interviews were related to dependence in self-care activities.

The interview results were consistent with the results from a similar studies conducted in the South Africa, in which the participants expressed limitations in self-care activities including bathing, dressing, and eating difficulties $^{7,25}$.

Being psychologically affected by the dependence in self-care activities was also found in another qualitative study carried out in Australia employing focus group discussions ${ }^{5}$. In longer term, the dependence in selfcare activities could lead to emotional challenges including depression, anger, suicidal thoughts and a sense of $\operatorname{loss}^{3}$. The present study findings suggest the need of rehabilitation strategies like occupational therapy to help the stroke patients achieving dependence in selfcare activities. In addition, support services to deal with the psychological problems associated with dependence are recommended.

The limitations in domestic life activities as reported by the participants were also found in other studies ${ }^{5,26}$. Pound et al. found that a frequent cause of disadvantage to people with stroke is the inability to do housework activities ${ }^{26}$. A study conducted in South Africa revealed that people with stroke have limitations in acquisition of necessities and caring for household objects ${ }^{23}$. Consequently, the limitations in domestic life activities could cause emotional problems such as depression and anger ${ }^{3}$. From the participants' expressions, one of the roles of professionals involved in stroke rehabilitation is to improve the ability to do domestic activities.

\section{Participation restrictions experienced}

The inability to return to previous occupation as a challenge experienced by stroke patients was also found in other various studies. For instance, a study conducted in South Africa by Rouillard et al. exploring functioning at 6 months post stroke following discharge from in- 
patient rehabilitation showed that the participants were not able to participate in all usual roles ${ }^{7}$. The challenge of inability to return to previous occupation could be associated with the inability to walk. According to Vestling et al., being unable to walk independently after stroke is a barrier to return to work ${ }^{27}$. To go in farms for cultivating, one must be able to walk and reach there. However, during the interviews, the participants expressed that they had difficulty to move out of their homes. The majority $(60 \%)$ of the participants were cultivators, and a disability clearly impacts on an individual's ability to do agricultural work ${ }^{28}$.

The consequent economic dependence described by participants is consistent with the findings from the focus group discussions conducted in Ruhengeri and Gisenyi provinces of Rwanda ${ }^{28}$. It was revealed that many persons with disabilities rely on gifts from friends and family. Considering the young age of the interview participants (the mean age of the sample was 56.3), which is below the pensionable age and falling into the economically active group of the population, the inability to perform usual social roles is more than individual. It is a major socio-economic issue because young patients are more often caring for dependants, and rely on work-related income ${ }^{29}$. The inability to return to previous occupation frequently leads to emotional and financial hardships for stroke survivors and their families. It was highlighted that complications including stress in the family, return to previous occupation and many future needs in a population affected by stroke at young age should be considered in rehabilitation planning for stroke patients. This would be in agreement with the recommendations by the United Nations which states that in both rural and urban areas, persons with disabilities must have equal opportunities for productive and gainful employment in the labor market ${ }^{30}$.

The decreased social interactions reported by the participants were also noted in many previous studies. Similar studies conducted in South Africa and Nigeria revealed that the majority of stroke patients are unable to participate in social and leisure activities ${ }^{7,31}$. Relationships are perceived to be important, not only for comfort and support, but also for maintaining a sense of continuity $^{2}$. The decreased social interactions experienced by the participants would have a negative impact on social support networks, while these networks have a positive influence on a stroke patient's functional and psychoso- cial recovery ${ }^{2}$. With regard to the feelings of decreased social interactions, there is a need of community based or outreach rehabilitation services such as the community health centers, day programmes or home visits for stroke rehabilitation in Rwanda.

Loss of participation in religious activities was also reported in a study conducted in the United Kingdom ${ }^{8}$. This is most likely a consequence of difficulty in walking as discussed earlier. While the participants expressed their difficulties to attend religious activities in churches, it was reported that prayer, religious beliefs and involvement with church communities provide some stroke patients with a sense of perspective about their disease as well as providing social support ${ }^{3}$. The current study population which is psychologically affected by the stroke itself, the dependence in activities of daily living, and the social isolation may therefore develop more anxiety and depression which could be prevented by having an opportunity to take part in church activities $^{32}$. Therefore, the study findings suggest that there is need for specific rehabilitation programmes to address the factors limiting the participation in various social activities by the stroke survivors.

Although the present study provides useful information that can guide clinicians and policy makers in develop ing the rehabilitation strategies for people with stroke, the individuals with communication or cognition problems were excluded from the interview sample. Therefore, the qualitative sample may only represent a group of individuals while the excluded group might have different experiences. Hence, future study design should consider having a more representative sample. Furthermore, the study participants were selected from only one out of 30 districts of Rwanda, and consequently the results cannot be generalized for the whole country. Future similar studies should be extended to cover the whole country.

Finally, future data analysis should consider the member check strategy to better assess the credibility of the data interpretation.

\section{Conclusion}

The study findings revealed that after the discharge from the hospital to their homes, stroke patients experience various activity limitations and participation restrictions including the limitations in walking, limitations in self-care activities, limitations in domestic life 
activities, inability to return to previous occupation, decreased social interactions, and inability to participate in religious activities. Greater understanding of the impact of stroke on activity and participation is important to facilitate planning appropriate rehabilitation services in order to improve the functional status of people with stroke.

\section{Acknowledgements}

I am grateful to Prof. Anthea Rhoda for her advice during the planning and implementation of the study. I also thank the authorities who permitted me to conduct this study, and the study participants

\section{References}

1. Warlow C, Dennis MS, van Gijn J, Hankey GJ, Sandercock PAG. Stroke: A practical guide to management. Oxford, UK: Blackwell Science, 2001.

2. Salter K, Hellings C, Foley N, Teasell R. The experience of living with stroke: A qualitative meta-synthesis. Journal of Rehabilitation Medicine 2008, 40(8), 595-602.

3. Ch'Ng AM, French D, Mclean N. Coping with the Challenges of Recovery from Stroke: Long Term Perspectives of Stroke Support Group Members. Journal of Health Psychology 2008, 13(8), 1136-1146.

4. Pearson OR, Busse ME, van Deursen RWM, Wiles CM. Quantification of walking mobility in neurological disorders. Quarterly Journal of Medicine (QJM): $A n$ International Journal of Medicine 2004, 97(8), 463-475.

5. Pajalic Z, Karlsson S, Westergren A. Functioning and subjective health among stroke survivors after discharge from hospital. Journal of Advanced Nursing 2006, 54(4), 457-466.

6. van de Port IGL, Kwakkel G, van Wijk I, Lindeman E. Susceptibility to Deterioration of Mobility LongTerm After Stroke: A Prospective Cohort Study. Stroke 2006, 37(1), 167-171.

7. Rouillard S, De Weerdt W, De Wit L, Jelsma J. Functioning at 6 months post stroke following discharge from inpatient rehabilitation. The South African Medical Journal 2012, 102(6), 545-548.

8. Dowswell G, Lawler J, Dowswell T, Young J, Forster A, Hearn J. Investigating Recovery from Stroke: a qualitative study. Journal of Clinical Nursing 2000, 9(4), 507-515.

9. Pollack MRP, Disler PB. Rehabilitation of patients after stroke. The Medical Journal of Australia 2002, 177(8), 444-448.
10. Kengne AP, Amoah AG, Mbanya JC. Cardiovascular complications of diabetes mellitus in Sub-Saharan Africa. Circulation 2005, 112(23), 3592-3601.

11. Musanze District. Agriculture. 2012a; (cited 2015 March 17). Available from: http://www.musanze.gov. rw/index.php?id $=975$

12. Musanze District. Vulnerable groups. 2009; (cited 2014 July 24). Available from: http:// www.musanze. gov.rw/

13. Musanze District. Tourism. 2012b; (cited 2015 March 17). Available from: http://www.musanze.gov. $\mathrm{rw} /$ index.php?id $=946$

14. Graneheim U, Lundman B. Qualitative content analysis in nursing research: concepts, procedures and measures to achieve trustworthiness. Nurse Education Today 2004, 24(2), 105-112.

15. Neumann W. Social Research Methods. Qualitative and Quantitative Methods. Boston: Ally and Bacon Publishers, 2000.

16. Jones S. The analysis of depth interviews. In R. Walker (Ed.), Applied Qualitative Research (pp. 56-70). Aldershot, UK: Gower Publishing, 1985.

17. Miles MB, Huberman AM. Qualitative data analysis: A sourcebook of new methods. Beverly Hills, CA: Sage, 1984.

18. Shenton AK. Strategies for ensuring trustworthiness in qualitative research projects. Education for Information 2004, 22(2), 63-75.

19. Graneheim U, Lundman B. Qualitative content analysis in nursing research: concepts, procedures and measures to achieve trustworthiness. Nurse Education Today 2004, 24(2), 105-112.

20. Lincoln YS, Guba EA. Naturalistic inquiry. Beverly Hills, CA: Sage, 1985.

21. Krefting L. Rigor in Qualitative Research: The Assessment of Trustworthiness. The American Journal of Occupational Therapy 1991, 45(3), 214-222.

22. Hendricks HT, van Limbeek J, Geurts AC, Zwarts MJ. Motor recovery after stroke: a systematic review. $A r$ chives of Physical Medicine and Rehabilitation 2002, 83(11), 1629-1637.

23. Rhoda A. Limitations in Activit y and Participation experienced by stroke patients: A Qualitative Inquiry. SA Journal of Physiotherapy 2012, 68(3), 20-24.

24. Hamzat TK, Okesola YA. Some clinical and psychosocial determinants of independent walking attainment by post stroke patients. African Journal of Neurological Sciences 2006, 25(1), 59-66.

25. Joseph C, Rhoda A. Activity limitations and factors 
influencing functional outcome of patients with stroke following rehabilitation at a specialised facility in the Western Cape. African Health Sciences 2013, 13(3), 646654

26. Pound P, Gompertz P, Ebrahim S. A patient-centred study of the consequences of stroke. Clinical Rehabilitation 1998, 12(4), 338-347.

27. Vestling M, Tufvesson B, Iwarsson S. Indicators for return to work after stroke and the importance of work for subjective well-being and life satisfaction. Journal of Rehabilitation Medicine 2003, 35(3), 127-131.

28. Thomas P. Mainstreaming Disability in Development: Country-level research. Rwanda Country Report. 2005; (cited 2015 March 17). Available from: www.disabilitykar.net/docs/rwanda_ex.doc
29. Graham JR, Kruger E, Teasell R, Foley N, Salter K. The Rehabilitation of Younger Stroke Patients. 2008; (cited 2015 March 17). Available from: http://www. ebrsr.com/reviews_details.php?6

30. United Nations (UN). The Standard Rules on the Equalization of Opportunities for Persons with Disabilities. New York: UN, 1993.

31. Vincent-Onabajo GO. Social Participation after Stroke: One-Year Follow-Up of Stroke Survivors in Nigeria.2013; (cited 2015March17). Available from: http:/ / www.hindawi.com/journals/isrn/2013/532518/

32. Mueller PS, Plevak DJ, Rummans TA. Religious involvement, spirituality and medicine: implication for clinical practice. Mayo Clinic Proceedings 2001, 76(12), 1225-1235. 